\title{
The impact of surgically induced ischaemia on protein levels in patients undergoing rectal cancer surgery
}

\author{
GK Atkin ${ }^{*,}$, FM Daley', S Bourne', R Glynne-Jones ${ }^{2}$, JMA Northover ${ }^{3}$ and GD Wilson ${ }^{4}$ \\ 'Gray Cancer Institute, Mount Vernon Hospital, Northwood, Middlesex HA6 2RN, UK; ${ }^{2}$ Department of Radiotherpy, Mount Vernon Hospital, Northwood, \\ Middlesex HA6 2RN, UK; ${ }^{3}$ Colorectal Cancer Unit, St Mark's Hospital, Harrow HAI 3UJ, UK; ${ }^{4}$ Karmanos Cancer Institute, Wayne State University, \\ Detroit, MI 48201-2013, USA
}

The goal of targeted therapy has driven a search for markers of prognosis and response to adjuvant therapy. The surgical resection of a solid tumour induces tissue ischaemia and acidosis, both potent mediators of gene expression. This study investigated the impact of colorectal cancer (CRC) surgery on prognostic and predictive marker levels. Tumour expression of thymidylate synthase, thymidine phosphorylase, cyclin A, vascular endothelial growth factor (VEGF), carbonic anhydrase-9, hypoxia inducible factor-I $\alpha$, and glucose transporter-I (GLUT-I) proteins was determined before and after rectal cancer surgery. Spectral imaging of tissue sections stained by immunohistochemistry provided quantitative data. Surgery altered thymidylate synthase protein expression $(P=0.02)$, and this correlated with the change in the proliferation marker cyclin A. The expression of hypoxia inducible factor- $\mid \alpha$, VEGF, and GLUT- I proteins was also different following surgery. Colorectal cancer surgery significantly impacts on intratumoral gene expression, suggesting archival specimens may not accurately reflect in situ marker levels. Although rectal cancer was the studied model, the results may be applicable to any solid tumour undergoing extirpation in which molecular markers have been proposed to guide patient therapy.

British Journal of Cancer (2006) 95, 928 -933. doi:I0.1038/sj.bjc.6603362 www.bjcancer.com

(c) 2006 Cancer Research UK

Keywords: colorectal cancer; gene expression; thymidylate synthase; hypoxia

There has been considerable recent interest in markers of tumour prognosis and response to adjuvant therapy in a range of tumour types, including colorectal cancer (CRC). It is hoped these markers will allow targeted tumour therapy while minimising the toxicity of inefficacious agents. Thymidylate synthase (TS) is a key enzyme in DNA synthesis and is the main site of action of the chemotherapeutic agent 5-fluorouracil (5-FU) (van der Wilt and Peters, 1994). It is the most widely studied prognostic and predictive marker in CRC, with low TS levels predicting a better outcome to 5-FU based chemotherapy (Aschele et al, 2002), and high TS expression being associated with a poor prognosis (Allegra et al, 2003). However, previous reports of TS display methodological heterogeneity, in that TS expression within preoperative biopsies (Okonkwo et al, 2001) as well as postoperative archival tumour sections (Edler et al, 2000), has been correlated with treatment outcome.

The resection of a solid tumour, such as a CRC, often involves early clamping of the vascular pedicle to facilitate the surgical dissection and aid tumour extirpation. Interrupting the vascular inflow leads to tumour hypoxia and acidosis (Parkins et al, 1997), both of which are potent mediators of gene expression (Helfman and Falanga, 1993). In addition, delays in tissue fixation following

*Correspondence: Dr GK Atkin, 70 Rosebery Rd, Muswell Hill, London NI02LA, UK; E-mail: gkatkin@blueyonder.co.uk

Received II January 2006; revised I5 August 2006; accepted I5 August 2006 extirpation reduce the efficacy of subsequent protein and mRNA analysis (Almeida et al, 2004).

We have previously shown in an experimental CRC model that tumour vascular clamping significantly alters gene expression levels (Atkin et al, 2006). There are no formal clinical guidelines regarding the rapidity of tumour fixation following extirpation, and if CRC surgery and tissue processing methods do alter gene expression levels, it may be that marker expression in postoperative tumour samples does not reflect true in situ levels. Therefore, the aim of this study was to determine the effect of surgery on marker expression in patients with CRC, looking in particular at changes in thymidylate synthase. The relationships between TS expression and the levels of cyclin A, a cell proliferation marker, and the hypoxia-related protein hypoxia inducible factor- $1 \alpha$ (HIF-1 $\alpha)$ are also presented.

\section{MATERIALS AND METHODS}

\section{Study patients}

Patients undergoing surgical resection of histologically proven rectal cancer were recruited over a 2 -year period. There were no exclusion criteria. Standard curative resections and anaesthetic techniques were performed in all cases. Local ethics committee approval was obtained and all patients gave informed consent.

Five preoperative tumour samples were obtained on the day of surgery, immediately prior to the surgical resection. A further five biopsies were obtained immediately following tumour extirpation. 
In addition, for each patient a control sample of rectal mucosa was obtained before and after surgery, at the same time as tumour biopsies. Tumour and mucosal sampling was confirmed by examination of haematoxylin and eosin stained sections by an independent, experienced histopathologist.

Each tumour and control mucosal biopsy was stored in $10 \%$ neutral buffered formalin solution (Sigma, Poole, UK) for subsequent protein analysis by immunohistochemistry. For all patients, the duration of tumour ischaemia (defined as time of arterial pedicle clamping until postoperative biopsy) was noted, as well as the time between extirpation and postoperative tumour sampling. In all cases, the true clinical duration of tumour ischaemia was longer than that noted in this study, as the postoperative biopsies were obtained before actual fixation of the surgical specimen by the operating theatre staff.

\section{Immunohistochemistry}

Table 1 shows the proteins and the conditions used for immunohistochemistry. Sections $(4 \mu \mathrm{m})$ were dewaxed in xylene for $5 \mathrm{~min}$ and rehydrated through graded alcohol (100, 90, and $70 \%)$ to water. Heat mediated antigen retrieval was performed using $250 \mathrm{ml} 10 \mathrm{~mm}$ citric acid $\mathrm{pH} 6$ for all markers, apart from vascular endothelial growth factor (VEGF) (0.1 M Tris-HCL pH 10) and CA-9 (no pretreatment), by boiling the sections in an $800 \mathrm{~W}$ microwave oven (Panasonic NN-6453BBPQ, $2450 \mathrm{MHz}$ ).

For all markers apart from CA- 9 and HIF- $1 \alpha$, sections were transferred to the DAKO Autostaining machine (DAKO, UK) containing peroxidase block (DAKO, S2023), the detection reagents (ChemMate HRP, DAKO K5001), and anti-human primary antibody diluted in antibody diluent. The Autostainer programme included $5 \mathrm{~min}$ in peroxidase block, $1 \mathrm{~h}$ incubation in primary antibody, $30 \mathrm{~min}$ incubation in ChemMate secondary and tertiary reagents and $5 \mathrm{~min}$ in diaminobenzidine (DAB) substrate.

Sections were stained for HIF- $1 \alpha$ using the DakoCytomation CSA II signal amplification system (DAKO Corporation, Carpinteria, USA). In summary, the sections were first incubated with $3 \%$ hydrogen peroxide for $5 \mathrm{~min}$ to quench endogenous peroxidase activity, following which incubation with a protein block for $5 \mathrm{~min}$ was performed to inhibit nonspecific binding. Diluted primary antibody was added and sections were incubated for $15 \mathrm{~min}$. Sequential 15-minute incubations were performed with anti-mouse Ig-HRP, fluorescyl-tyramide hydrogen peroxide, and antifluorescein-HRP. Finally, the slides were incubated for $5 \mathrm{~min}$ with DAB/ hydrogen peroxide. For CA-9, endogenous peroxidase activity was blocked using DAKO peroxidase block (Envision kit) for $5 \mathrm{~min}$. Then a DAKO Protein Block (X0909) was added for a further 5 min, following which incubation with the CA-9 primary antibody diluted $1 / 50$ in Tris-buffered saline for 30 mins was performed. A further incubation was then performed with DAKO Envision HRP Mouse polymer (K4006) for $30 \mathrm{~min}$, followed by $5 \mathrm{~min}$ with DAB solution.

When the programme was complete, stained slides were removed from the machine and counterstained in Gills
Haematoxylin (Surgipath Europe Ltd, 01500E) for $5 \mathrm{~s}$. Slides were then washed in tap water, dehydrated in graded alcohols (70, 90, and $100 \%$ ), cleared in xylene and mounted in DPX (Surgipath Europe Ltd, 08600E). Each staining run incorporated a control slide that had previously demonstrated positive for the antibody of interest. A negative control was also incorporated and involved the substitution of the anti-human primary antibody for an isotypic control antibody at the same protein concentration.

\section{Quantification of marker protein expression}

Immunohistochemical staining of marker protein expression was quantified using a spectral imager developed and constructed in our Institute, as reported previously (Barber et al, 2003). This allowed accurate immunostain quantification, with stain intensity being expressed as optical density (OD) normalised to reference spectra. Most markers demonstrated greater expression in tumour compared with stroma, so nonspecific background staining could be minimised by applying arbitrary thresholds to the OD data. For markers exhibiting similar tumour and stromal staining, a threshold was chosen that included the staining of both tissue compartments. In addition, the number of pixels with stain intensity above the threshold was determined and represented the area of the captured image demonstrating marker expression. A standard image capture protocol was used to ensure the maximum tumour/stroma ratio was obtained for each image, which allowed comparison of stained area between captured images.

Two images were captured for each of the five biopsies taken before and after surgery, and for each captured image the stain intensity and area were determined by spectral imaging. The change in marker stain intensity was given by the difference between mean stain intensity after surgery $(\mathrm{Ma})$ and mean before $(\mathrm{Mb})$, whereas the change in the number of pixels demonstrating marker expression was given by $\mathrm{Pa}-\mathrm{Pb}$. Hence, a positive difference implies greater marker expression after surgery. Cyclin A is a nuclear antigen and HIF-1 $\alpha$ showed mixed nuclear and cytoplasmic staining. Therefore, a labelling index (ratio of positive to negative nuclei) was calculated by counting stained cells within each captured image for HIF- $1 \alpha$ and cyclin A, and the change in nuclear score for these markers was given by the difference between mean labelling index before and after surgery.

\section{Statistics}

The Wilcoxon signed ranks test was used to determine the magnitude of overall deviation from zero of the difference between pre- and postoperative marker levels, where a significant deviation from zero would suggest an effect of surgery on marker expression. The sign test was used to calculate the significance of the deviation with respect to direction. A $P$-value of $<0.05$ was taken to represent significance. Spearman's rank correlation coefficient, $r_{\mathrm{s}}$, was used to determine the nonparametric correlation between variables.

Table I Markers studied, and conditions for immunohistochemistry

\begin{tabular}{|c|c|c|c|}
\hline Antibody & Pretreatment & Dilution & Source of antibody \\
\hline Thymidylate synthase (TS) & $4 \times 4$ min microwave in citric acid with 10 min standing & $1 / 300$ & Simon Joel, London, UK \\
\hline Cyclin A & $3 \times 4$ min microwave in citric acid with 10 min standing & $1 / 100$ & \#NCL-CYCLIN A, Novocastra Labs Ltd, UK \\
\hline Thymidine phosphorylase (TP) & None & $1 / 400$ & \#MS-499-P0, NeoMarkers Inc., USA \\
\hline Carbonic anhydrase-9 (CA-9) & None & $1 / 50$ & Adrian Harris, Oxford, UK \\
\hline Glucose transporter-I (GLUT-I) & $3 \times 4$ min microwave in citric acid with 10 min standing & $1 / 200$ & \#A3536, DAKO Corporation, USA \\
\hline Hypoxia inducible factor- $\mid \alpha(\mathrm{HIF}-\mid \alpha)$ & $4 \times 4$ min microwave in citric acid with 20 min standing & $1 / 1000$ & \#ab463-100, Abcam Ltd, UK \\
\hline Vascular endothelial growth factor (VEGF) & $3 \times 4$ min microwave in Tris- $\mathrm{HCl}$ with 10 min standing & $1 / 100$ & \#MS-350-PI, NeoMarkers Inc., USA \\
\hline
\end{tabular}




\section{RESULTS}

Samples were obtained from 30 patients undergoing rectal cancer surgery. Six patients were excluded as they had had neoadjuvant 5-FU based chemoradiation and subsequent biopsy examination revealed no residual tumour. Therefore, data for 24 untreated patients (median age 70, range 49-86; 16 male, 8 female) were available for protein analysis. The patient characteristics are shown in Table 2.

\section{The effect of CRC surgery on tumour protein expression}

The overall changes in marker stain intensity and area are given in Figures $1 \mathrm{~A}$ and $\mathrm{B}$. Thymidylate synthase stain intensity in postoperative biopsies was significantly different than biopsies taken before surgery $(P=0.02)$, suggesting an effect of surgery on the level of TS expression. For most patients there was a reduction in stain intensity after surgery, but this direction of change was not significant (16 patients with reduced expression postoperatively $v s$ 8 patients with increased expression; $P=0.15$ ). Thymidylate synthase stain area also differed following surgery $(P=0.04)$, with most patients showing a reduction in area (17 vs 7 patients; $P=0.06)$. Surgery also reduced cyclin A expression $(P=0.01)$, but the direction of change was not significant (18 vs 6 patients; $P=0.2$ ). The only other marker to demonstrate a change in stain intensity following surgery was the HIF- $1 \alpha$ nuclear count, which increased postoperatively (magnitude: $P=0.002$; direction: $P=0.007)$. GLUT-1 and VEGF stain area were altered by surgery $(P=0.004$ and 0.03 respectively), with most patients showing increased expression of GLUT-1 postoperatively (19 vs 5; $P=0.007)$.

\section{The effect of CRC surgery on control protein expression}

The only marker to show altered protein expression within samples of normal rectal mucosa was CA-9, which demonstrated

Table 2 Data for patients included in the analysis

\begin{tabular}{|c|c|c|c|c|c|c|}
\hline Patient & $\begin{array}{c}\text { Age } \\
\text { (years) }\end{array}$ & Sex & $\begin{array}{l}\text { Tumour } \\
\text { level (cm } \\
\text { from } \\
\text { anus) }\end{array}$ & $\begin{array}{c}\text { Histological } \\
\text { stage }\end{array}$ & $\begin{array}{l}\text { Duration } \\
\text { of } \\
\text { ischaemia } \\
\text { (min) }\end{array}$ & $\begin{array}{c}\text { Duration } \\
\text { of } \\
\text { extirpation } \\
\text { (min) }\end{array}$ \\
\hline I & 77 & $\mathrm{~F}$ & 13 & T3 No & 26 & 15 \\
\hline 2 & 72 & M & 10 & T3 N2 & 49 & 3 \\
\hline 3 & 58 & M & 15 & T2 No & 140 & 125 \\
\hline 4 & 64 & M & 10 & T3 NI & 65 & 60 \\
\hline 5 & 74 & $\mathrm{~F}$ & 15 & T4 N2 & 70 & 35 \\
\hline 6 & 60 & $M$ & 10 & T3 No & 75 & 15 \\
\hline 7 & 59 & $M$ & 15 & T3 N2 & 125 & 60 \\
\hline 8 & 80 & M & 5 & T3 No & 70 & 20 \\
\hline 9 & 57 & M & 13 & T3 NI & 80 & 55 \\
\hline 10 & 71 & $\mathrm{~F}$ & 15 & T3 No & 38 & 20 \\
\hline 11 & 62 & $M$ & 14 & T3 NO & 60 & 25 \\
\hline 12 & 77 & $M$ & 12 & T2 No & 120 & 55 \\
\hline 13 & 63 & M & 2 & T2 NI & 75 & 23 \\
\hline 14 & 86 & $\mathrm{~F}$ & 13 & T3 No & 50 & 25 \\
\hline 15 & 49 & $\mathrm{~F}$ & 14 & $\mathrm{~T} 2 \mathrm{NO}$ & 90 & 65 \\
\hline 16 & 82 & $\mathrm{~F}$ & 3 & T3 NI & 65 & 15 \\
\hline 17 & 68 & $\mathrm{~F}$ & 12 & T3 NO & 55 & 20 \\
\hline 18 & 71 & M & 10 & T3 No & 55 & 15 \\
\hline 19 & 78 & M & 15 & T3 No & 130 & 70 \\
\hline 20 & 76 & $\mathrm{~F}$ & 5 & T3 N2 & 80 & 45 \\
\hline 21 & 68 & $M$ & 13 & T3 NO & 70 & 35 \\
\hline 22 & 64 & M & 15 & T3 NO & 85 & 45 \\
\hline 23 & 77 & $M$ & 15 & T3 No & 50 & 35 \\
\hline 24 & 55 & $M$ & 14 & T4 N2 & 100 & 15 \\
\hline Median & 69.5 & & 13 & & 70 & 30 \\
\hline Range & $49-86$ & & $2-15$ & & $26-140$ & $3-125$ \\
\hline
\end{tabular}

a reduction in stain area following surgery (magnitude: $P=0.009$; direction: $P=0.02$ ).

\section{Correlations with durations of ischaemia and extirpation,} and with the tumour level

The median duration of tumour ischaemia was $70 \mathrm{~min}$ (range 26140), while the median time between extirpation and postoperative tumour sampling was $30 \mathrm{~min}$ (range 3-125). There was no correlation between the change in expression and the durations of ischaemia or extirpation for any marker studied. Correlations for TS are given in Figures 2A and B. There was also no correlation between the changes in stain intensity and area and the tumour level above the anal verge. The poor correlation between changes in hypoxic marker expression and tumour level would suggest there was no direct relationship between ischaemic insult and the degree of residual vascular inflow from the middle and inferior rectal arteries following clamping of the main vascular pedicle.
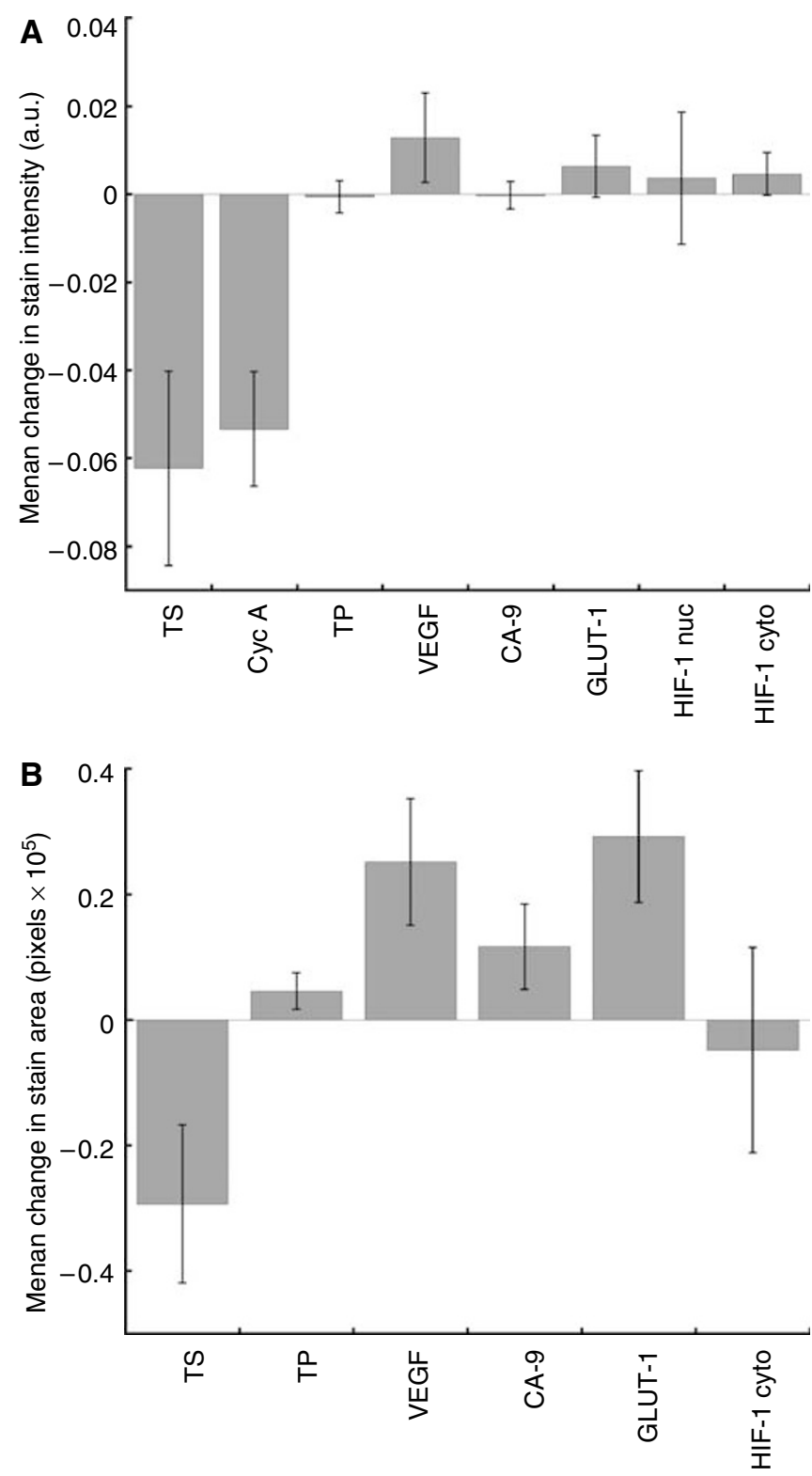

Figure I Overall changes in marker stain intensity $((\mathbf{A})$ arbitrary units, a.u.) and area (B) following surgery (error bars denote s.e.). 

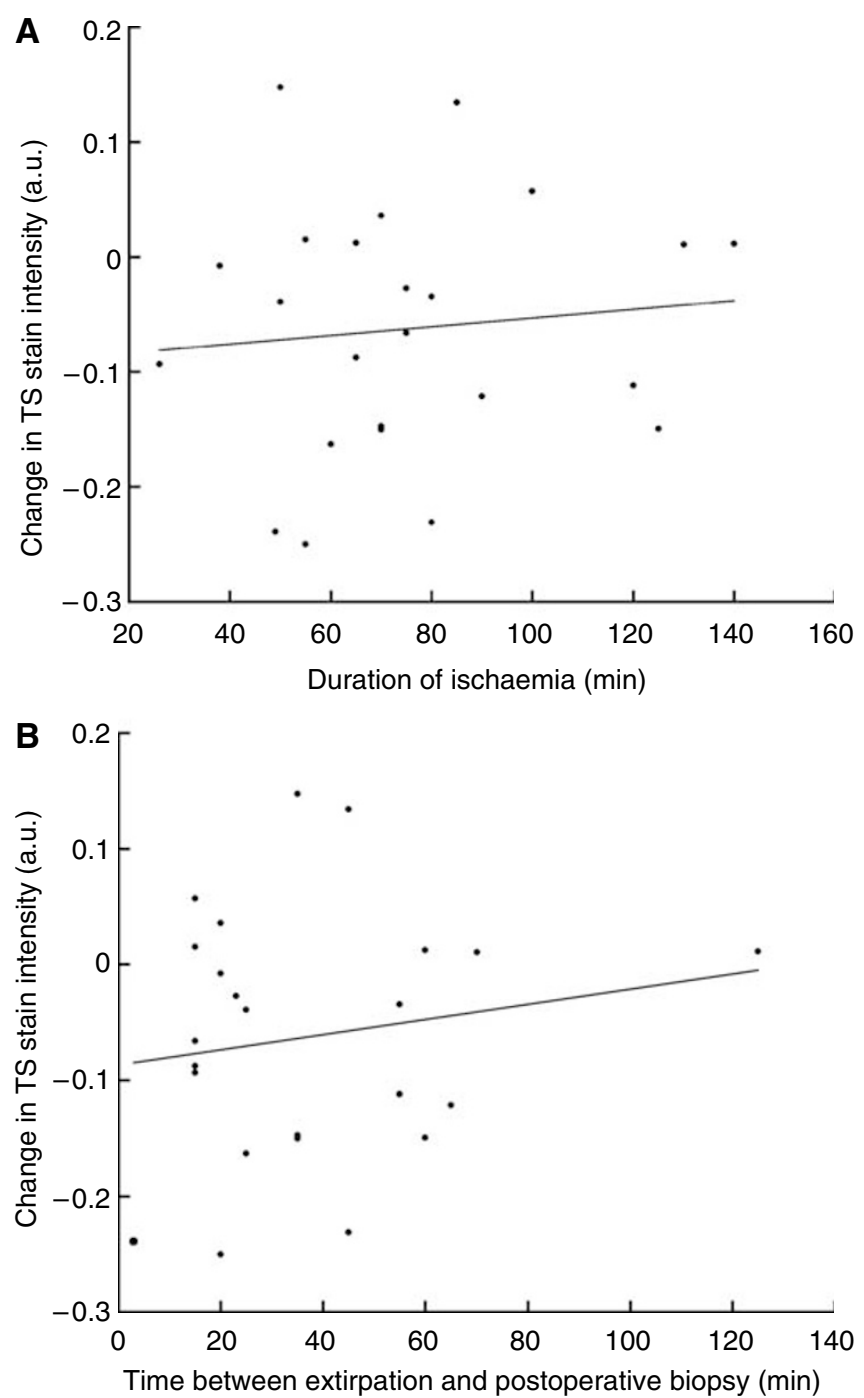

Figure 2 Correlation between changes in TS stain intensity (a.u.) and duration of ischaemia $\left((\mathbf{A}) r_{\mathrm{s}}=0.12, P=0.58\right)$ and extirpation ((B) $\left.r_{\mathrm{s}}=0.06, P=0.77\right)$.

\section{Correlations between TS expression and the markers of proliferation and hypoxia}

Thymidylate synthase stain area correlated with cyclin A expression $\left(r_{\mathrm{s}}=0.61, P=0.002\right)$, suggesting changes in TS mirrored changes in cell proliferation. Thymidylate synthase stain area also correlated with cytoplasmic HIF- $1 \alpha$ and GLUT-1 stain area ( $r_{\mathrm{s}}=0.73, P<0.0001 ; r_{\mathrm{s}}=0.49, P=0.02$ respectively), whereas the correlation between TS stain intensity and nuclear HIF- $1 \alpha$ expression approached significance $\left(r_{\mathrm{s}}=0.39, P=0.06\right)$.

\section{Impact of surgery on immunohistochemical visual grading scores}

Spectral imaging is a novel method of immunostain quantification, and as such is not widely available. The most common method of quantifying immunohistochemical staining patterns is by visual estimation of marker stain intensity and area. Figures $3 \mathrm{~A}$ and $\mathrm{B}$ show the magnitude and direction of the changes in TS expression after surgery in relation to these manual visual grades. The limits for the visual grades are given in Table 3 and were derived by analysis of a subset of patients and reported in a previous study (Atkin et al, 2005). Although these limits are somewhat arbitrary, it
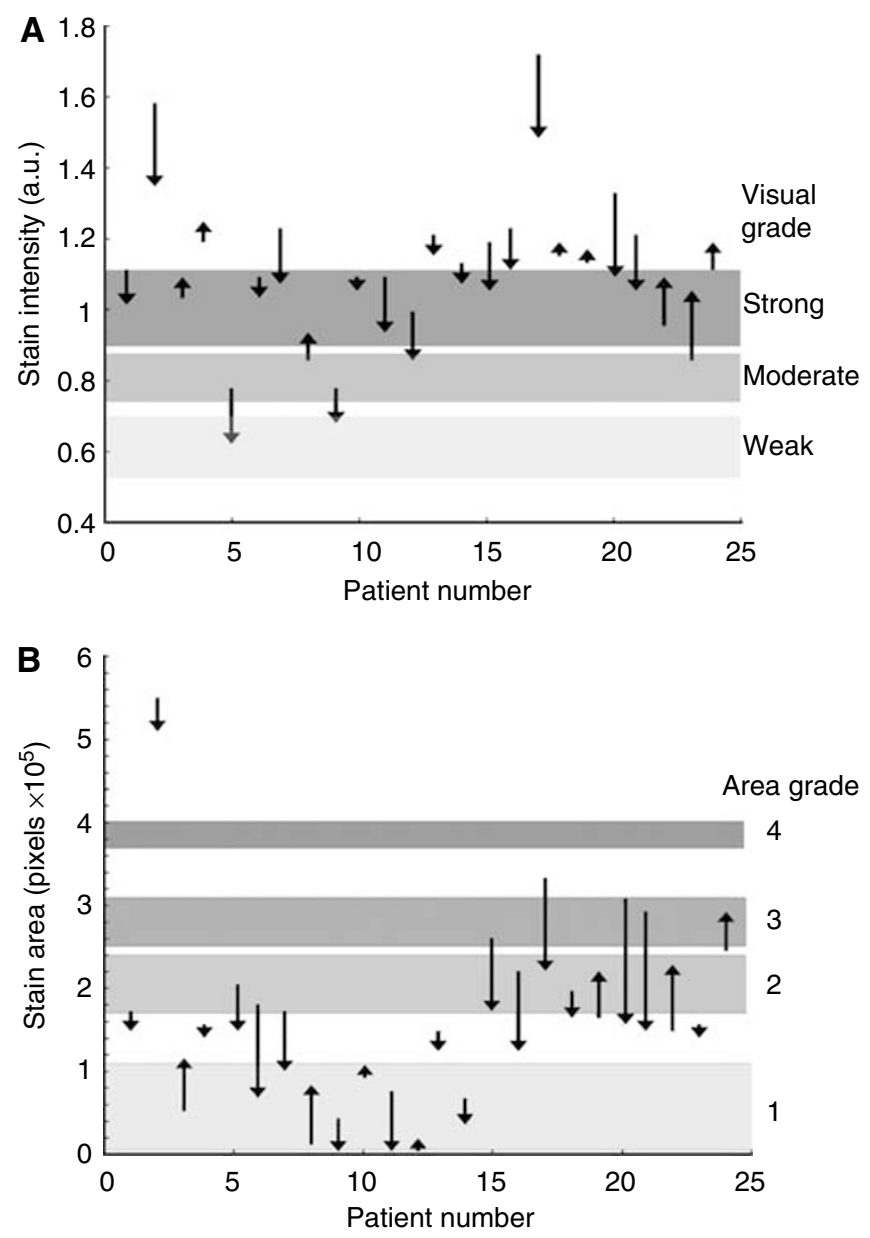

Figure 3 The changes in TS visual stain intensity $(\mathbf{A})$ and area $(\mathbf{B})$ scores occurring during CRC surgery. The length and the bearing of the arrows represent the magnitude and direction of the change in TS expression between pre- and postoperative biopsies.

Table 3 Spectral stain intensity and area limits for each visual grade (visual intensity score represents overall TS stain intensity, visual area score denotes the percentage of the section staining positively for TS)

\begin{tabular}{lcccc}
\hline Grade & $\mathbf{I}$ & $\mathbf{2}$ & $\mathbf{3}$ & $\mathbf{4}$ \\
\hline Visual intensity score & Negative & Weak & Moderate & Strong \\
Spectral intensity range (a.u.) & 0 & $0.53-0.66$ & $0.75-0.88$ & $0.91-1.1$ I \\
Visual area score & $<20 \%$ & $20-50 \%$ & $50-75 \%$ & $>75 \%$ \\
Spectral area range $\left(\right.$ pixels $\left.\times 10^{5}\right)$ & $0.02-1.1$ & $1.7-2.4$ & $2.5-3.1$ & $3.7-4.0$ \\
\hline
\end{tabular}

is evident the visual intensity score is different in five patients after surgery compared with the preoperative score, whereas in six patients the visual area grades are different postoperatively. These visual scores are widely used to grade the expression of markers such as TS, and in future may be involved in guiding management decisions based on marker expression. These results suggest that surgery may alter these visual scores, and hence there may be discrepancies in marker expression in archival tumour samples compared with in situ levels.

\section{DISCUSSION}

This study investigated the change in gene expression occurring during the surgical resection of primary rectal cancer. Warm 
ischaemia has been shown to alter the gene expression profile of a range of tissue types (Miyatake et al, 2004), and transcriptional changes following extirpation have been demonstrated for multiple genes within a microarray of colorectal mucosal samples beginning 20 min after excision (Huang et al, 2001). Extirpation was not shown to have an affect on DPD enzyme activity in CRC samples (Sadahiro et al, 2003); however, delays in fixation following excision have been shown to impair the analysis of the oestrogen receptor (ER) status in breast cancer patients (Von Wasielewski et al, 1998).

We found CRC surgery significantly altered intratumoural biomarker levels, with TS showing the greatest response. There was a trend towards a reduced expression of TS following surgery, and it was interesting to note the correlation between TS and the proliferation marker cyclin $\mathrm{A}$, a finding also seen previously in an experimental model of surgically induced CRC ischaemia (Atkin et al, 2006). In fact, TS has been suggested to be a marker of cell proliferation, as it is induced during the G1 phase of the cell cycle and levels increase 20 -fold as cells enter the S phase (Santi et al, 1974). Hypoxia slows the metabolic rate and is associated with lower levels of transcription and translation (Dachs and Tozer, 2000); hence, the reduction in TS levels seen after surgery may be related to the effect of tumour ischaemia on the proliferation status.

Thymidine phosphorylase (TP) is an enzyme involved in thymidine homeostasis and is involved in the activation and metabolism of the fluoropyrimidines, including 5-FU. It is also known as platelet derived endothelial cell growth factor, and has been shown to promote angiogenesis (Miyazono et al, 1987). High tumour TP levels have been shown to correlate with poor prognosis (van Triest et al, 2000), and response to 5-FU (Metzger et al, 1998) in CRC patients. In our study, CRC surgery did not appear to have an effect on TP expression. Previous work has demonstrated TP protein induction by hypoxia in a breast carcinoma cell line (Griffiths et al, 1997), but only after $16 \mathrm{~h}$ and there was no induction with oxygen concentrations greater than $0.3 \%$. The same study also detected an increased TP expression after $2 \mathrm{~h}$ of vascular clamping in a breast tumour xenograft model. Our data, however, suggest that the degree and duration of tumour ischaemia is insufficient to alter TP levels in rectal cancer patients undergoing surgery, which is an important finding and suggests archival specimens are appropriate for TP analysis.

The absolute intratumoral oxygen tensions were not measured in this study, and so it is not possible to document the degree of ischaemia for each tumour following arterial clamping. This will vary depending on tumour level and anatomical differences in collateral blood supply. Hypoxia-related markers were measured in an attempt to determine the ischaemic insult. Hypoxia-inducible factor-1 is a transcription factor involved in oxygen homeostasis. It was noted there were changes in HIF- $1 \alpha$ expression, with a significant upregulation in HIF- $1 \alpha$ nuclear protein expression postoperatively. The cytoplasmic protein expression was unaltered. However, hypoxia results in translocation of the HIF-1 complex to the nucleus to allow DNA binding (Bos et al, 2004), and so one would expect an increased differential nuclear expression. Carbonic anhydrase-9 (CA-9) is a downstream mediator of HIF-1 activation induced by hypoxia (Wykoff et al, 2000). There were no changes in CA-9 expression noted in this study. However, cell line data (Lal et al, 2001) suggest the duration of ischaemia noted in our patients was not long enough to cause CA-9 induction. Vascular endothelial growth factor and glucose transporter-1 (GLUT-1) are also products of HIF-1 activation, and CRC surgery did have an effect on the expression of both these markers. Taken together, these data indicate a considerable tumour hypoxic insult during vascular clamping.

In an experimental model of surgically induced CRC ischaemia, TS expression correlated directly with cyclin A and inversely with CA-9 (Atkin et al, 2006), suggesting greater TS downregulation occurred at lower oxygen tensions secondary to a decreased cell proliferation. The direct correlation between TS and HIF- $1 \alpha$ expression noted in this study therefore appears paradoxical. It may be that other microenvironmental factors, such as acidosis or alterations in the availability of glucose and other enzymatic substrates, are more active in human tumours, thereby affecting the level of TS or HIF- $1 \alpha$ expression. Alternatively, it may relate to the role of HIF-1 in hypoxiainduced growth arrest (Goda et al, 2003), or the regulation of TS by other factors, such as p53 or E2F-1, which are induced by hypoxia and are involved in TS regulation (Ash et al, 1995). It was interesting to note there was no correlation for any marker between the change in expression and the durations of ischaemia and extirpation, suggesting a complex interplay between gene expression and the tumour microenvironment following vascular clamping.

The findings of this study have important implications on the timing of biomarker measurement in relation to the surgical procedure. They suggest the need for guidelines on specimen fixation following excision, and the importance of methodological standardisation of studies investigating prognostic and predictive markers, particularly if they are to be used to dictate therapeutic strategy. The results are relevant as standard surgical techniques were used and the tumour processing methods were those encountered in everyday practice. In fact, the duration of tumour ischaemia was shorter in all cases than that occurring in actual clinical practice.

Several potential sources of error were encountered. The tumour/stroma ratio varied between captured images, making it difficult to compare directly the stained area between tumour sections. However, a standard protocol for image capture was followed, ensuring each captured image contained the maximum available tumour tissue. Solid tumours show architectural heterogeneity, with varying levels of hypoxia and acidosis throughout the tissue. This introduces sampling error when measuring gene expression levels in biopsy specimens. This was minimised as far as possible by multiple sampling before and after surgery, and determining the mean marker level at each time point. Gene expression profiles of tumour biopsies are representative of the whole tumour (Perou et al, 2000); hence, the changes in expression seen should be applicable to the whole lesion.

The effects of tissue processing must be considered when using immunohistochemistry to measure marker levels. Tumour fixation occurs at unpredictable rates, and may take days depending on the fixative and the size of the specimen (Heyderman et al, 1989). Similarly, protein crosslinking during tissue fixation may alter the antigenic determinants, whereas antigen retrieval techniques may 'unmask' unrelated antigens (Heyderman et al, 1989). To reduce protein degradation during processing, large specimens should be incised to expedite fixation, or a representative tumour sample should fixed immediately and used for subsequent protein quantification. Alternatively, where delays in fixation are unavoidable, refrigeration of the specimen may minimise the loss of immunoreactivity.

\section{CONCLUSIONS}

In patients undergoing rectal cancer surgery, significant changes in gene expression were noted between pre- and postoperative tumour biopsies. These findings have important considerations when investigating prognostic markers and markers predicting the response to adjuvant therapy. These data suggest the duration of tumour ischaemia should be minimised prior to fixation, and that subsequent studies need to standardise prognostic and predictive marker measurement in relation to the surgical procedure. 


\section{ACKNOWLEDGEMENTS}

We thank Dr Paul Richman, Consultant Histopathologist at Mount Vernon Hospital, Northwood, Middlesex, for the confirmation of tumour and mucosal sampling within pre- and postoperative

\section{REFERENCES}

Allegra CJ, Paik S, Colangelo LH, Parr AL, Kirsch I, Kim G, Klein P, Johnston PG, Wolmark N, Wieand HS (2003) Prognostic value of thymidylate synthase, Ki-67, and p53 in patients with Dukes' B and C colon cancer: a National Cancer Institute-National Surgical Adjuvant Breast and Bowel Project collaborative study. J Clin Oncol 21(2): $241-250$

Almeida A, Paul Thiery J, Magdelenat H, Radvanyi F (2004) Gene expression analysis by real-time reverse transcription polymerase chain reaction: influence of tissue handling. Anal Biochem 328(2): $101-108$

Aschele C, Lonardi S, Monfardini S (2002) Thymidylate synthase expression as a predictor of clinical response to fluoropyrimidine-based chemotherapy in advanced colorectal cancer. Cancer Treat Rev 28(1): $27-47$

Ash J, Liao WC, Ke Y, Johnson LF (1995) Regulation of mouse thymidylate synthase gene expression in growth-stimulated cells: upstream $S$ phase control elements are indistinguishable from the essential promoter elements. Nucleic Acids Res 23(22): 4649-4656

Atkin G, Barber P, Vojnovic B, Daley F, Glynne-Jones R, Wilson G (2005) Correlation of spectral imaging and visual grading for the quantification of thymidylate synthase protein expression in rectal cancer. Hum Pathol 36(12): $1302-1308$

Atkin G, Daley FM, Bourne S, Glynne-Jones R, Northover J, Wilson GD (2006) The effect of surgically induced ischaemia on gene expression in a colorectal cancer xenograft model. Br J Cancer 94(1): 121-127

Barber P, Vojnovic B, Atkin G, Daley F, Everett S, Wilson G, Gilbey J (2003) Applications of cost-effective spectral imaging microscopy in cancer research. J Phys D 36: 1729-1738

Bos R, van Diest PJ, van der Groep P, Shvarts A, Greijer AE, van der Wall E (2004) Expression of hypoxia-inducible factor-1alpha and cell cycle proteins in invasive breast cancer are estrogen receptor related. Breast Cancer Res 6(4): R450-R459

Dachs GU, Tozer GM (2000) Hypoxia modulated gene expression: angiogenesis, metastasis and therapeutic exploitation. Eur J Cancer 36(13 Spec No): $1649-1660$

Edler D, Hallstrom M, Johnston PG, Magnusson I, Ragnhammar P, Blomgren H (2000) Thymidylate synthase expression: an independent prognostic factor for local recurrence, distant metastasis, disease-free and overall survival in rectal cancer. Clin Cancer Res 6(4): 1378- 1384

Goda N, Ryan HE, Khadivi B, McNulty W, Rickert RC, Johnson RS (2003) Hypoxia-inducible factor lalpha is essential for cell cycle arrest during hypoxia. Mol Cell Biol 23(1): 359-369

Griffiths L, Dachs GU, Bicknell R, Harris AL, Stratford IJ (1997) The influence of oxygen tension and $\mathrm{pH}$ on the expression of platelet- derived endothelial cell growth factor/thymidine phosphorylase in human breast tumor cells grown in vitro and in vivo. Cancer Res 57(4): 570-572

Helfman T, Falanga V (1993) Gene expression in low oxygen tension. Am J Med Sci 306(1): 37-41

Heyderman E, Warren PJ, Haines AM (1989) Immunocytochemistry today - problems and practice. Histopathology 15(6): 653-658 biopsies. This work was funded by The Freemasons' 250th Anniversary Fund, a Royal College of Surgeons of England Research Fellowship, and by the Rob Glynne-Jones Cancer Research Fund.

Huang J, Qi R, Quackenbush J, Dauway E, Lazaridis E, Yeatman T (2001) Effects of ischemia on gene expression. J Surg Res 99(2): 222-227

Lal A, Peters H, St Croix B, Haroon ZA, Dewhirst MW, Strausberg RL, Kaanders JH, van der Kogel AJ, Riggins GJ (2001) Transcriptional response to hypoxia in human tumors. J Natl Cancer Inst 93(17): $1337-1343$

Metzger R, Danenberg K, Leichman CG, Salonga D, Schwartz EL, Wadler S, Lenz HJ, Groshen S, Leichman L, Danenberg PV (1998) High basal level gene expression of thymidine phosphorylase (platelet-derived endothelial cell growth factor) in colorectal tumors is associated with nonresponse to 5-fluorouracil. Clin Cancer Res 4(10): 2371-2376

Miyatake Y, Ikeda H, Michimata R, Koizumi S, Ishizu A, Nishimura N, Yoshiki T (2004) Differential modulation of gene expression among rat tissues with warm ischemia. Exp Mol Pathol 77(3): 222-230

Miyazono K, Okabe T, Urabe A, Takaku F, Heldin CH (1987) Purification and properties of an endothelial cell growth factor from human platelets. J Biol Chem 262(9): 4098-4103

Okonkwo A, Musunuri S, Talamonti M, Benson 3rd A, Small Jr W, Stryker SJ, Rao MS (2001) Molecular markers and prediction of response to chemoradiation in rectal cancer. Oncol Rep 8(3): 497-500

Parkins CS, Hill SA, Stratford MR, Dennis MF, Chaplin DJ (1997) Metabolic and clonogenic consequences of ischaemia reperfusion insult in solid tumours. Exp Physiol 82(2): $361-368$

Perou CM, Sorlie T, Eisen MB, van de Rijn M, Jeffrey SS, Rees CA, Pollack JR, Ross DT, Johnsen H, Akslen LA, Fluge O, Pergamenschikov A, Williams C, Zhu SX, Lonning PE, Borresen-Dale AL, Brown PO, Botstein D (2000) Molecular portraits of human breast tumours. Nature 406(6797): $747-752$

Sadahiro S, Suzuki T, Ishikawa K, Nakamura T, Kamijo A, Saguchi T, Yasuda S, Tajima T, Makuuchi H, Murayama C (2003) The stability of dihydropyrimidine dehydrogenase activity in colorectal cancer tissue after resection. Oncol Rep 10(4): 867-869

Santi DV, McHenry CS, Sommer H (1974) Mechanism of interaction of thymidylate synthetase with 5-fluorodeoxyuridylate. Biochemistry 13(3): $471-481$

van der Wilt CL, Peters GJ (1994) New targets for pyrimidine antimetabolites in the treatment of solid tumours. 1: thymidylate synthase. Pharm World Sci 16(2): $84-103$

van Triest B, Pinedo HM, Blaauwgeers JL, van Diest PJ, Schoenmakers PS, Voorn DA, Smid K, Hoekman K, Hoitsma HF, Peters GJ (2000) Prognostic role of thymidylate synthase, thymidine phosphorylase/ platelet-derived endothelial cell growth factor, and proliferation markers in colorectal cancer. Clin Cancer Res 6(3): 1063-1072

Von Wasielewski R, Mengel M, Nolte M, Werner M (1998) Influence of fixation, antibody clones and signal amplification on steroid receptor analysis. Breast J 4: $33-40$

Wykoff CC, Beasley NJ, Watson PH, Turner KJ, Pastorek J, Sibtain A, Wilson GD, Turley H, Talks KL, Maxwell PH, Pugh CW, Ratcliffe PJ, Harris AL (2000) Hypoxia-inducible expression of tumor-associated carbonic anhydrases. Cancer Res 60(24): 7075-7083 